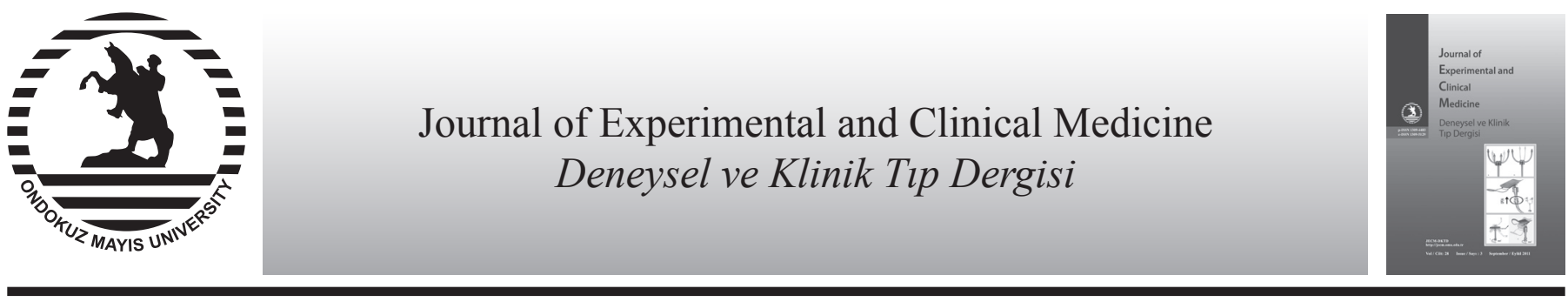

Experimental Research

doi: $10.5835 /$ jecm.omu.28.03.001

\title{
Effects of experimental diabetes on testis proliferations and apoptosis in rats
}

\author{
Cevat Aktaş $^{a^{*}}$, Mehmet Kanter ${ }^{\mathrm{b}}$, Mustafa Erboğa ${ }^{\mathrm{b}}$, Hüseyin Timurkan ${ }^{\mathrm{c}}$ \\ ${ }^{a}$ Department of Histology and Embryology, Faculty of Medicine, Namik Kemal University, Tekirdă̆, Turkey \\ ${ }^{b}$ Department of Histology and Embryology, Faculty of Medicine, University of Trakya, Edirne, Turkey \\ ${ }^{c}$ Department of Obstetrics and Gynecology, Faculty of Veterinary Medicine, Firat University, Elaziğ, Turkey
}

\begin{tabular}{|c|c|c|}
\hline \multicolumn{2}{|c|}{ ARTICLE INFO } & ABSTRACT \\
\hline \multirow{3}{*}{\multicolumn{2}{|c|}{$\begin{array}{ll}\text { Article History } \\
\text { Received } & 21 / 06 / 2011 \\
\text { Accepted } & 27 / 06 / 2011\end{array}$}} & med to investigate the role of diabetes on cell proliferation, and apoptosis in \\
\hline & & re randomly allotted into one of t \\
\hline & & diabetic group; each group contain 10 animals. Diabetes was induced by a single intra- \\
\hline \multirow{7}{*}{\multicolumn{2}{|c|}{$\begin{array}{l}\text { * Correspondence to } \\
\text { Cevat Aktaş, } \\
\text { Department of Histology and Embryology, } \\
\text { Faculty of Medicine, } \\
\text { Namik Kemal University, } \\
\text { Tekirdag, Turkey } \\
\text { e-mail: cevata@yahoo.com }\end{array}$}} & matoxylin and eosin, immunohistochemical staining of proliferating cell nuclear antigen \\
\hline & & (PCNA), and apoptosis was determined by terminal-deoxynucleotidyl-transferase medi- \\
\hline & & dUTP nick end labeling (TUNEL). Potential disorders associated with seminiferous \\
\hline & & tubular sperm formation were evaluated using the Johnsen score. The mean seminiferous \\
\hline & & tubule diameter (MSTD) and mean testicular biopsy score (MTBS) values were signifi- \\
\hline & & $\begin{array}{l}\text { cantly decreased in diabetic group was compared to the control group. Our dat } \\
\text { a significant reduction in the expression of PCNA and an enhancement in the }\end{array}$ \\
\hline & & TUNEL in testis tissues of the diabetic group. The effects of diabetes on spermatogenesis \\
\hline \multirow{2}{*}{\multicolumn{2}{|c|}{$\begin{array}{l}\text { Keywords: } \\
\text { Experimental diabetes }\end{array}$}} & 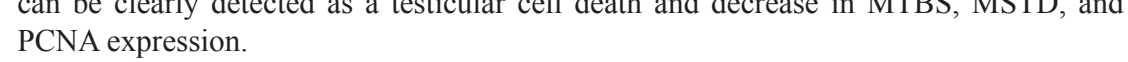 \\
\hline Experimental diabetes & & J. Exp. Clin. Med., 2011; 28:94-98 \\
\hline
\end{tabular}

Testis

TUNEL

Immunohistochemistry

PCNA

Rat

C 2011 OMU All rights reserved

\section{Introduction}

Diabetes mellitus is a common health problem and a serious metabolic disorder associated with many functional and structural complications. Diabetes mellitus has adverse effects on male sexual and reproductive functions in diabetic patients and animals (Sainio-Pollanen et al., 1997; Sexton et al., 1997; Baker et al., 1998; Meyer et al., 2000).

Male reproductive alterations have been widely reported in model animals and human with diabetes (Ballester et al., 2004). Streptozotocin induced diabetes in male rats resulted atrophy of sex organ, changes in histoarchitecture of ventral prostate, diminution in sperm count (Sing et al., 2005), along with low levels in plasma gonadotrophins (Seethalakshmi et al., 1987) and testosterone (Sanguinetti et al., 1985). The copulatory behavior of diabetic rat has been collapsed along with low fertility in induced normal mating (Scarano et al., 2006). In human, diabetes is associated with erectile dysfunction (Takahashi et al., 1997) along with loss of libido (Kim et al., 2006) and abnormal morphology of sperm, low plasma levels of gonadotrophins and testosterone (Dinulvic et al., 1990).
Apoptosis, known as programmed cell death, is a form of cell death that serves to eliminate dying cells in proliferating or differentiating cell populations. Apoptosis control is critical for normal spermatogenesis in the adult testis (Oksanen, 1975; Sinha Hikim and Swerdloff 1999). The testis is sensitive to environmental exposure-induced cellular damage. Apoptosis of germ cells may occur during nonphysiological stresses such as diabetes, ischemia, hyperthermia and radiation (Collin et al., 1996; Cai et al., 1997). Recent studies have shown increased apoptosis in the seminiferous tubule of streptozotocin (STZ)-induced diabetic mice and rats (Cai et al., 1997; Sainio-Pollanen et al., 1997; Cai et al., 2000). The mechanisms of diabetes-related apoptosis are unclear. However, current studies have indicated that diabetes-mediated oxidative stres can induce apoptosis (Allan et al., 1992; Reiter et al., 2000).

Proliferative cell nuclear antigen (PCNA) is a well-known $36-\mathrm{kD}$ nuclear matrix protein. It has been used as a marker for the DNA synthesis because of its maximal expression during the $\mathrm{S}$ and $\mathrm{G} 2$ phases of the cell cycle. It is only absent during the G0 phase. PCNA has a biological half-life of 20 hours. 
It is an auxillary protein of DNA polmerase and is involved in the repair of DNA. The efficiency of spermatogenesis depends on the proliferative activity of spermatogonia and the loss of germ cells during meiosis and spermiogenesis (Steger et al., 1998). PCNA is useful for the diagnosis of germinal arrest because there are significantly reduced PCNA levels in germinal arrest, which is an indication of DNA synthesis deterioration (Zeng et al., 2001).

The aim of the present study, a detailed histopathological examination was performed, the role of diabetes on cell proliferation, and apoptosis in rat testis.

\section{Material and methods}

\section{Animals}

Twenty healthy male Wistar albino rats, weighing 200-250 g and averaging 16 weeks old were utilized in this study. Rats were fed a standard rat chow and tap water ad libitum. In the windowless animal quarter automatic temperature $\left(22 \pm 2^{\circ} \mathrm{C}\right)$ and lighting controls (light on at $07 \mathrm{AM}$ and off at 09 PM: $14 \mathrm{~h}$ light $/ 10 \mathrm{~h}$ dark cycle) was performed. Humidity ranged from $50 \%$ to $55 \%$. All animals received human care according to the criteria outlined in the "Guide for the Care and Use of Laboratory Animals" prepared by the National Academy of Sciences and published by the National Institutes of Health. The study was approved by the Institutional Animal Ethical Committee of the Namik Kemal University, Tekirdag, Turkey.

\section{Experimental design}

The rats were randomly allotted into one of two experimental groups: control, and diabetic group; each group contain 10 animals.

\section{Experimental procedures}

Diabetes was induced by a single intraperitoneal (i.p.) injection of STZ $(50 \mathrm{mg} / \mathrm{kg}$, freshly dissolved in $5 \mathrm{mmol} / \mathrm{L}$ citrate buffer, $\mathrm{pH}$ 4.5). Two days after STZ treatment, development of diabetes was confirmed by measuring blood glucose levels in tail vein blood samples. Rats with blood glucose levels of $250 \mathrm{mg} / \mathrm{dL}$ or higher were considered to be diabetic. Diabetes was confirmed by Ames One Touch Glucometer (LifeScan, Johnson and Johnson, New Brunswick, NJ, USA). Control rats were injected with the same volume of isotonic $\mathrm{NaCl}$ as the diabetic animals that received STZ.

At the end of the experiment, all animals were anesthetized by intraperitoneally administration of $90 \mathrm{mg} / \mathrm{kg}$ ketamine and $10 \mathrm{mg} / \mathrm{kg}$ xylazine. The anesthetized rats were sacrificed after 8 weeks and testis tissues were removed for histopathological investigation.

\section{Histopathologic evaluation}

The testis specimens were embedded in the paraffin blocks after they had been fixed in Bouin's solution. Sections of 5 $\mu \mathrm{m}$ were obtained, deparaffinized and stained with hematoxylin and eosin (H\&E). The testis tissue was examined and evaluated in random order under blindfold conditions with standard light microscopy. Three slides prepared from the upper, lower, and midportions of the testis were evaluated completely for each testis. Mean seminiferous tubule diameter (MSTD) was measured in micrometers. Spermatogenesis was assessed histopathologically using Johnsen's mean testicular biopsy score (MTBS) criteria (Johnsen, 1970). A score of $0-10$ was given to each tubule according to epithelial maturation. Testicular injury and spermatogenesis were graded as described by Johnsen (1970). A score of 1 indicated no seminiferous epithelial cells and tubular sclerosis. A score of 2 indicated no germ cells, only Sertoli cells. A score of 3 indicated spermatogonia only. A score of 4 indicated no spermatids, few spermatocytes, and an arrest of spermatogenesis at the primary spermatocyte stage. A score of 5 indicated no spermatids and many spermatocytes. A score of 6 indicated no late spermatids, few early spermatids, an arrest of spermatogenesis at the spermatid stage, and a disturbance of spermatid differentiation. A score of 7 indicated no late spermatids and many early spermatids. A score of 8 indicated few late spermatids. A score of 9 indicated many late spermatids and a disorganized tubular epithelium. A score of 10 indicated full spermatogenesis. Preparations were evaluated with a bright field microscope (Nikon Optiphot 2, Tokyo) and photographed.

Evaluation of germ cell apoptosis

Germ cell apoptosis were evaluated by the TUNEL assay. The TUNEL method, which detects fragmentation of DNA in the nucleus during apoptotic cell death in situ, was employed using an apoptosis detection kit (TdT-FragelTM DNA Fragmentation Detection Kit, Cat. No. QIA33, Calbiochem, USA). All reagents listed below are from the kit and were prepared following the manufacturer's instructions. Five- $\mu \mathrm{m}$ thick testis tissue sections were deparaffinized in xylene and rehydrated through a graded ethanol series as described previously. They were then incubated with $20 \mathrm{mg} / \mathrm{ml}$ proteinase $\mathrm{K}$ for 20 minutes and rinsed in TBS. Endogenous peroxidase activity was inhibited by incubation with $3 \%$ hydrogen peroxide. Sections were then incubated with equilibration buffer for 10-30 second and then TdT-enzyme, in a humidified atmosphere at $37^{\circ} \mathrm{C}$, for 90 minutes. They were subsequently put into pre-warmed working strength stop/wash buffer at room temperature for 10 minutes and incubated with blocking buffer for 30 minutes. Each step was separated by thorough washes in TBS. Labelling was revealed using DAB, counter staining was performed using Methyl green, and sections were dehydrated, cleared and mounted.

Quantitative analysis of testicular apoptosis in control, and diabetic groups was estimated according to $\mathrm{Hu}$ et al. (2003). To quantity the incidence of apoptosis, the seminiferous tubules containing three or more apoptotic cells by TUNEL stain were calculated. The apoptosis percentage was calculated by the ratio of the positive seminiferous tubules of apoptosis to the total number of seminiferous tubules in a cross section.

\section{Immunohistochemical staining}

The harvested testis tissues were fixed in Bouin's, embedded in paraffin and sectioned at $5 \mu \mathrm{m}$ thickness. Immunocytochemical reactions were performed according to the $\mathrm{ABC}$ technique described by Hsu et al., (1981). The procedure involved the following steps: (1) endogenous peroxidase activity was inhibited by $3 \% \mathrm{H}_{2} \mathrm{O}_{2}$ in distilled water for $30 \mathrm{~min}$; (2) the sections were washed in distilled water for $10 \mathrm{~min}$; (3) non-specific binding of antibodies was blocked by incubation with normal goat serum (DAKO X 0907, Carpinteria, CA) with PBS, diluted 1:4; (4) the sections were incubated with specific monoclonal anti-PCNA antibody (Cat. \# MS-106-B, Thermo LabVision, USA) diluted 1:50 for $1 \mathrm{~h}$ at room temperature; (5) the sections were washed in PBS $3 \times 3$ min; (6) the sections were incubated with biotinylated anti-mouse $\operatorname{IgG}$ 
(DAKO LSAB 2 Kit); (7) the sections were washed in PBS 3 $\times 3 \mathrm{~min}$; (8) the sections were incubated with ABC complex (DAKO LSAB 2 Kit); (9) the sections were washed in PBS $3 \times 3 \mathrm{~min}$; (10) peroxidase was detected with an aminoethylcarbazole substrate kit (AEC kit; Zymed Laboratories); (11) the sections were washed in tap water for $10 \mathrm{~min}$ and then dehydrated; (12) the nuclei were stained with hematoxylin; and (13) the sections were mounted in DAKO paramount. All dilutions and thorough washes between steps were performed using phosphate buffered saline unless otherwise specified. All steps were carried out at room temperature unless otherwise specified. As a negative control, primary antibody was replaced with PBS.To quantity the incidence of PCNA, 10 seminiferous tubules were counted in each slide. The cells with brown nuclear staining were considered positive. Both stained and nonstained germ cells were counted, and the ratio of stained cells to the total number of germ cells, "PCNA index," was calculated for each seminiferous tubule. The average PCNA index in each case was obtained by dividing the sum of all PCNA indices by the number of seminiferous tubules in which the calculation was carried out (Altay et al., 2003).

\section{Statistical analysis}

All statistical analyses were carried out using SPSS statistical software (SPSS for windows, version 11.0). All data were presented in mean $( \pm$ ) standard deviations (S.D.). Differences in measured parameters among the three groups were analyzed with a nonparametric test (Kruskal-Wallis). Dual comparisons between groups exhibiting significant values were evaluated with a Mann-Whitney U-test. These differences were considered significant when probability was less than 0.05 .

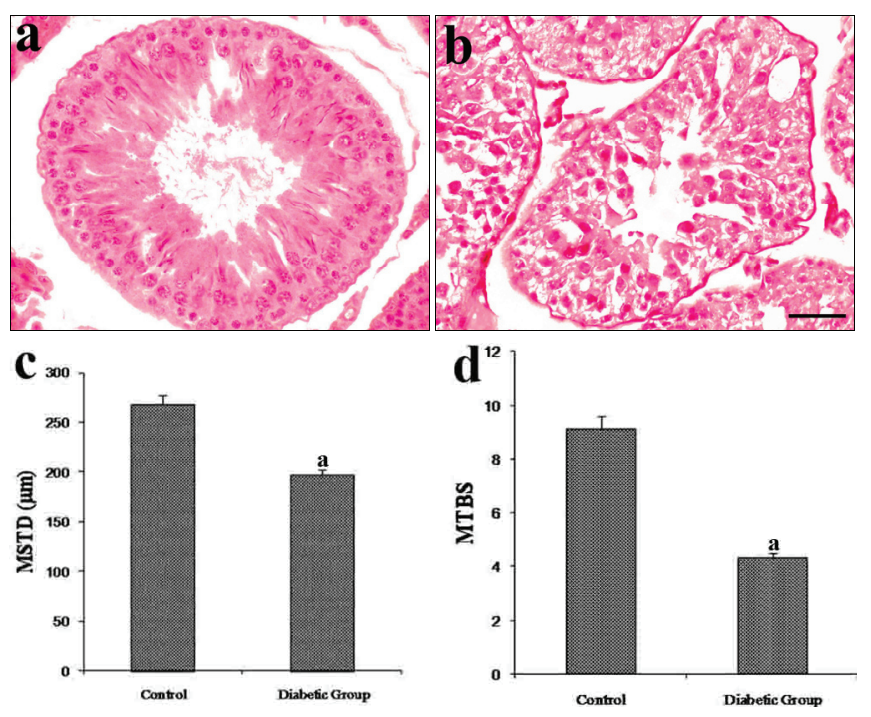

Fig. 1. Light microscopy of testicular tissue in different groups. (a): In controls, normal testicular architecture was seen; (b): After STZ induced, severe testicular damage was noted (H\&E, scale bar, $50 \mu \mathrm{m})$. (c,d): MSTD and MTBS level of control and diabetic rats. It was observed that the MSTD and MTBS level of the diabetic group were statistically significantly lower when compared to control group, $(\mathrm{a}, \mathrm{p}<0.01)$.

\section{Results}

\section{Histopathological changes}

Control testes showed the presence of normal testicular ar- chitecture and regular seminiferous tubular morphology with normal spermatogenesis (Fig. 1a). In the testes of diabetic rats, the size of the seminiferous tubules was strongly reduced when the morphology of the epithelium was severely impaired. Also in diabetic rats, atrophy of the tubules with varying degree of spermatogenetic arrest was detected (Fig. 1b).

The MSTD and MTBS values for testis in each group are shown in Table 1. Interestingly, it was observed that the MSTD and MTBS of the diabetic group were statistically significantly lower when compared to control group $(\mathrm{P}<0.01)$, (Fig. 1c, d).

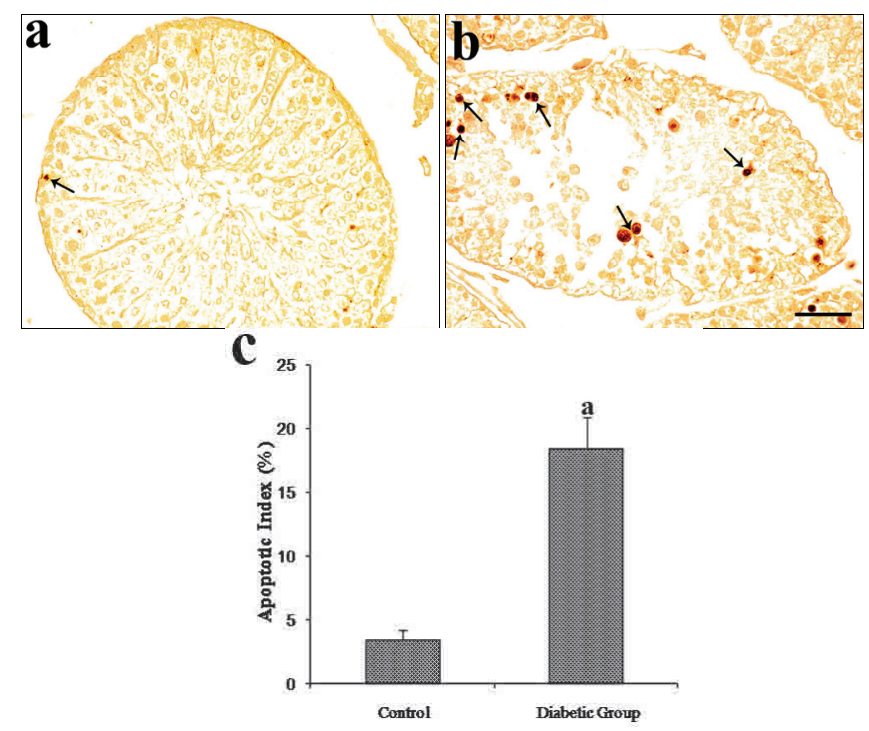

Fig. 2. Representative photographs of TUNEL staining in testes of control (a) and STZ-induced diabetic rats (b). Positive cells of TUNEL staining were increased in diabetic rats. Arrows indicate positive cells. Scale bars $=50 \mu \mathrm{m}$. (c), Quantitative analysis of apoptosis in the testes. The apoptosis index was calculated as the ratio of apoptosis-positive seminiferous tubules to the total number of seminiferous tubules. (a,p $<$ 0.01 ) compared to control group.

\section{Evaluation of germ cell apoptosis}

Apoptotic cells in testes of control and diabetic rats were identified by TUNEL staining. Only a few TUNEL-positive cells were observed in control animals (Fig. 2a). However, the number and signal density of TUNEL-positive germ cells significantly increased in diabetic rats (Fig. 2b). The apoptotic index was significantly increased in the diabetic group, compared to that of controls $(\mathrm{P}<0.01)$, (Fig. $2 \mathrm{c}$ ).

Evaluation of Immunohistochemical Staining

PCNA-positive cells were strongly detected in the spermatogonia and early-stage spermatocytes of the control rats (Fig. 3a). The number of PCNA-positive germinal cells was lower in diabetic group than control group (Fig. 3b). The PCNA index was significantly decreased in the diabetic group, compared to that of controls $(\mathrm{P}<0.05)$, (Fig. 3c).

\section{Discussion}

In the testicular tissue, MTBS is used to assess histopathological damage. It is based on the evaluation of progressive degeneration of the germinal epithelium (Johnsen, 1970; Uguralp et al., 2004). In the present study, the lowest MTBS values in testes were found in diabetic group. Another histo- 


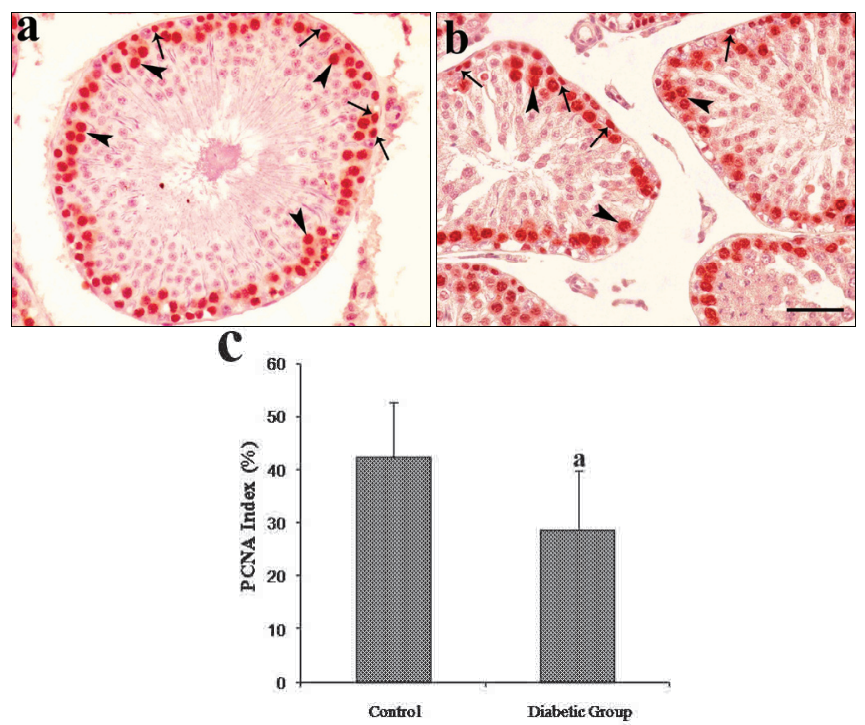

Fig. 3. Testicular immunostaining for PCNA in different groups. (a): In controls, PCNA positive cells were strongly detected in spermatogonia and early-stage spermatocytes. (b): The number of PCNA-positive germinal cells was lower in STZinduced diabetic group than control group. Arrow: Spermatogonia, Arrowhead: Early-stage spermatocytes. Immunoperoxidase, haematoxylin counterstain, scale bar, $50 \mu \mathrm{m}$. (c): The PCNA indices of the control and diabetic groups. The PCNA index was calculated as the ratio of PCNA-positive seminiferous tubules to the total number of seminiferous tubules. $(\mathrm{a}, \mathrm{p}<0.05)$ compared to control group.

pathological criterion of testicular damage used in the present study was the MSTD value, which is also used in the scientific literature to estimate testicular tissue damage (Uguralp et al., 2004). In the present study, the lowest MSTD value was also observed in diabetic group, which is similar to results obtained for MTBS values and is in accordance with previous studies (Altay et al., 2003).

In this study, the size of the seminiferous tubules was strongly reduced when the morphology of the epithelium was severely impaired. Also in diabetic rats, atrophy of the tubules with varying degree of spermatogenetic arrest was detected. This observation is in agreement with previous studies (Ricci et al., 2009).

PCNA expressed in spermatogonia and early phase primary spermatocytes in all stages of the seminiferous tubules (Kang et al., 1997) has been used previously to characterize testis tissues. The reduction in these cells caused by various compounds is attributed to the fact that the differentiation of spermatogonia is an especially vulnerable step in the spermatogenic process. For example, ethanol exposure decreases cell proliferation in the rat testes (Koh and Kim, 2006). In our results, PCNA-positive cells were detected in spermatogonia and early phase primary spermatocytes, regardless of the stage of the seminiferous tubules. The decrease of PCNA in testicular germ cells indicates the reduction of proliferative activity and spermatogenesis. In our present study, PCNApositive cells were strongly detected in spermatogonia and early-stage spermatocytes of control rats. However the signal density of positive cells was significantly lower in diabetic group. Salama et al., (1998) examined the impact of aging and non-insulin-dependent diabetes mellitus on the expression of the PCNA in rat testicular tissue, and they found that older animals showed the fewest number of immunostained basal germ cells in the seminiferous tubuli (Salama et al., 1998). Also in diabetic rats, the PCNA index was decreased in the dizbetic groups. This observation is in agreement with previous studies (Altay et al., 2003).

In this study, the number and signal density of TUNELpositive germ cells significantly increased and apoptotic index was significantly increased in the diabetic rats. This observation is in agreement with previous studies (Cai et al., 2000). It is well known that diabetes mellitus induces testicular dysfunction by causing apoptotic cell death, atrophy of the seminiferous tubules, decreased tubule diameters and reduction of spermatogenetic cell series (Cameron et al., 1985; Cai et al., 2000). Seminiferous tubule atrophy and the decrease in spermatogenic cells were morphological indicators of spermatogenesis failure (Cameron et al., 1985; Cai et al., 2000). Apoptosis plays a crucial role in the pathogenesis of testicular dysfunction in diabetic males (Cai et al., 2000). Specific DNA fragmentation at nucleosomal units is one of the most characteristic features of apoptosis (Wyllie et al., 1980). Detection of DNA fragments in situ using the TUNEL assay (Gavrieli et al., 1992) is undertaken to investigate active germ cell apoptosis induced by diabetes (Cai et al., 2000).

In conclusion, these findings suggest that significant reduction in the expression of PCNA and an enhancement in the activity of TUNEL in testis tissues of the diabetic group. The effects of diabetes on spermatogenesis can be clearly detected as a testicular cell death and decrease in MTBS, MSTD, and PCNA expression.

\section{REFERENCES}

Allan, D.J., Harmon, B.V., Roberts, S.A., 1992. Spermatogonial apoptosis has three morphologically recognizable phases and shows no circadian rhythm during normal spermatogenesis in the rat. Cell. Prolif. 25, 241-250.

Altay, B., Cetinkalp, S., Doganavşargil, B., Hekimgil, M., Semerci, B., 2003. Streptozotocin-induced diabetic effects on spermatogenesis with proliferative cell nuclear antigen immunostaining of adult rat testis. Fertil. Steril. 80, 828-831.

Baker, H.W., 1998. Reproductive effects of nontesticular illness. Endocrinol. Metab. Clin. North Am. 27, 831-850.

Ballester, J., Carmen Muñoz, M., Domínguez, J., Rigau, T., Guinovart, J.J., Rodríguez-Gil, J.E. 2004. Insulin-dependent diabetes affects testicular function by FSH- and LH-linked mechanisms. J. Androl. 25, 706-719.

Cai, L., Chen, S., Evans, T., Deng, D.X., Mukherjee, K., Chakrabarti, S., 2000. Apoptotic germ-cell death and testicular damage in experimental diabetes: prevention by endothelin antagonism. Urol. Res. 28, 342-347.

Cai, L., Hales, B.F., Robaire, B., 1997. Induction of apoptosis in the germ cells of adult male rats after exposure to cyclophosphamide. Biol. Reprod. 56, 1490-1497.

Cameron, D.F., Murray, F.T., Drylie, D.D., 1985. Interstitial compartment pathology and spermatogenic disruption in testes from impotent diabetic men. Anat. Rec. 213, 53-62.

Collin, O., Damber, J.E., Bergh, A., 1996. Effects of endothelin-1 on the rat testicular vasculature. J. Androl. 17, 360-366.

Dinulvic, D., Radonjit, G. 1990. Diabetes mellitus/male infertility. Arch. Androl. 25, 277-293.

Gavrieli, Y.S., Ben-Sasson, S.A., 1992. Identification of programmed cell death in situ via specific labeling of nuclear DNA fragmentation. J. 
Cell. Biol. 119, 493-501.

Hsu, S.M., Raine, L., Fanger, H., 1981. Use of avidin-biotin-peroxidase complex (ABC) in immunperoxidase techniques: a comparison between $\mathrm{ABC}$ and unlabeled antibody (PAP) procedures. J. Histochem. Cytochem. 29, 577-580.

Johnsen, S.G., 1970. Testicular biopsy score count - a method for registration of spermatogenesis in human testes. Normal values and results of 335 hypogonadal males. Hormones. 1, 2-25.

Kang, M.J., Kim, M.K., Terhune, A., Park, J.K., Kim, Y.H., Koh, G.Y., 1997. Cytoplasmic localization of cyclin D3 in seminiferous tubules during testicular development. Cell. Exp. Res. 234, 27-36.

Kim, N.N., Stankovic, M., Cushman, T.T., Goldstein, I., Munarriz, R., Traish, A.M., 2006. Streptozotocin-induced diabetes in the rat is associated with changes in vaginal hemodynamics, morphology and biochemical markers. BMC. Physiol. 6, 1-9.

Koh, P.O., Kim, M.O., 2006. Ethanol exposure decreases cell proliferation and increases apoptosis in rat testes. J. Vet. Med. Sci. 68, 10131017.

Meyer, K., Deutscher, J., Anil, M., Berthold, A., Bartsch Kiess, W., 2000. Serum androgen levels in adolescents with type I diabetes: relationship to pubertal stage and metabolic control. J. Endocrinol. Invest. 23, 362-368.

Oksanen, A., 1975. Testicular lesions of streptozotocin diabetic rats. Horm. Res. 6, 138-144.

Reiter, R.J., Tan, D.X., Osuna, C., Gitto, E., 2000. Actions of melatonin in the reduction of oxidative stress: a review. J. Biomed. Sci. 7, 444458.

Ricci, G., Catizone, A., Esposito, R., Pisanti, F.A., Vietri M.T., Galdieri, M., 2009. Diabetic rat testes: morphological and functional alterations. Andrologia. 41, 361-368.

Sainio-Pollanen, S., Henriksen, K., Parvinen, M., Simell, O., Pollanen, P., 1997. Stage-specific degeneration of germ cells in the seminiferous tubules of non-obese diabetic mice. Int. J. Androl. 20, 243-253.

Salama, M., Tsuji, M., Tamura, M., Kagawa, S., 1998. Impact of aging and diabetes mellitus on the expression of the proliferating cell nuclear antigen in rat testicular tissue. Arch. Androl. 40, 95-107.

Sanguinetti, R.E., Ogawa, K., Kurohmaru, M., Hayashi, I., 1995. Ultrastructural changes in mouse Leydig cells after streptozotocin administration. Exp. Anim. 44, 71-73.

Scarano, W.R., Messias, A.G., Oliva, S.U., Klinefeltert, G.R., Kempinas, W.G., 2006. Sexual behaviour, sperm quantity and quality after shortterm streptozotocin-induced hyperglycaemia in rats. Inter. J. Androl. 29, 482-488.

Seethalakshmi, L., Menon, M., Diamond, D., 1987. The effect of streptozotocin-induced diabetes on the neuroendocrine-male reproductive tract axis of the adult rat. J. Urol. 138, 190-194.

Sexton, W.F., Jarow, J.P., 1997. Effect of diabetes mellitus upon male reproductive function. Urology. 47, 508-513.

Sinha Hikim, A.P., Swerdloff, R.S., 1999. Hormonal and genetic control of germ cell apoptosis in the testis. Rev. Reprod. 4, 38-47.

Soudamani, S., Yuvaraj, S., Malini, T., Balasubramanian, K., 2005. Experimental diabetes has adverse effects on the differentiation of ventral prostate during sexual maturation of rats. Anatom Record Part A: Discov. Mol. Cell. Evol. Biol. 287, 1281-1289.

Steger, K., Aleithe, I., Behre, H., Bergman, M., 1998. The proliferation of spermatogonia in normal and pathological human seminiferous epithelium: an immunohistochemical study using monoclonal antibodies against Ki-67 protein and proliferating cell nuclear antigen. Mol. Hum. Reprod. 4, 227-233.

Takahashi, Y., Iwamoto, Y., 1997. Sexual dysfunction in diabetes mellitus. Nippo. Rinsho. 55, 2991-2995.

Uguralp, S., Bay, K.A., Mizrak, B., Kaymaz, F., Kiziltay, A., Hasirci, N., 2004. The effect of sustained and local administration of epidermal growth factor on improving bilateral testicular tissue after torsion. Urol. Res. 32, 323-331.

Wyllie, A.H., Kerr, J.F., Currie, A.R., 1980. Cell death: the significance of apoptosis. Int. Rev. Cytol. 68, 251-306.

Zeng, L., Kong, X.T., Su, J.W., Xia, T.L., Na, Y.Q., Guo, Y.L., 2001. Evaluation of germ-cell kinetics in infertile patients with proliferating cell nuclear antigen proliferating index. Asian. J. Androl. 3, 63-66. 